Article

\title{
Coping with Change: A Closer Look at the Underlying Attributes of Change and the Individual Response to Unstable Environments
}

\author{
Minke B.W. Langenhof * and Jan Komdeur \\ Behavioural Ecology and Self-Organization, Centre for Ecological and Evolutionary Studies, \\ University of Groningen, Nijenborgh 7, Groningen 9747 AG, The Netherlands; \\ E-Mail: j.komdeur@rug.nl
}

Author to whom correspondence should be addressed; E-Mail: m.b.w.langenhof@rug.nl;

Tel.: +31-50-363-2367.

Received: 20 March 2013; in revised form: 2 April 2013 / Accepted: 17 April 2013 /

Published: 25 April 2013

\begin{abstract}
Although the study of environmental change has long been of academic interest, the effects of change have become a much more pressing concern in the past few decades due to the often disruptive effect of human expansion and innovation. Researchers from many fields contribute to understanding our footprint on the natural world, problems we cause, and strategies we can employ to protect key species and ecosystems. Unfortunately, environmental change and its consequences are often studied without an awareness of the inherent attributes of the changes. As a result, the relevance of new advances in this field may be easily missed or misunderstood, and existing knowledge is not optimally applied. In this paper, we aim to facilitate the multi-disciplinary comparison of studies on environmental change, by offering a meta-level perspective on the process of change from the point of view of the individual animal. We propose an inclusive definition of change that can be applied across contexts, in which we take our understanding of "change" from an event to an interaction between a physical occurrence and an individual's state. Furthermore, we discuss key event- and individual-based attributes of change, their relevance in today's changing world, and how they relate to animals' available behavioural, physiological and cross-generational responses. We hope that by uncovering the underlying fundamental (or structure) of change, fellow scientists may better share their experience and knowledge gained from years of studying individual species and situations.
\end{abstract}

Keywords: environmental change; adaptation; behavioural plasticity, tolerance, state 


\section{Introduction}

Environmental change is a naturally occurring phenomenon, extensively studied by scientists for decades [1]. In many ecosystems, the environment changes with the seasons every year. Earthquakes, floods, fires, and similar geological or meteorological disturbances affect the adaptive landscape, as well. As a result, individual animals are continuously forced to cope with rapid fluctuations in temperature [2], precipitation [3], light availability [4], food sources [5,6], predation pressures [6], and habitat structure [7]. In fact, animals in natural populations are rarely, if ever, exposed to environments that are truly constant for any period of time. Over evolutionary time, many different behavioural and physiological mechanisms have evolved that allow animals to cope with and adapt to natural environmental fluctuations. For example, mechanisms like moult [8] and migration [5] allow many species to deal with annually predictable changes in their environment. Similarly, animals adjust their foraging behaviour, mate choice, parental effort or even the environment itself in order to adapt to their surroundings [9]. Animal regulatory systems are generally effective and versatile enough that animals can accommodate the mundane level of variability experienced within a lifetime [10].

This leaves scientists with the following questions: To what extent can animals still respond adequately when the level of variability within a lifetime increases, or annual events become less predictable? When does manageable change become unmanageable change, and how can we predict when environmental change will push species to extinction? Where are our conservation efforts best spent?

Recently, mainly due to concerns about the impact of our human influence on the environment [11-14], studying such questions about animals' ability to cope with change has become very popular in the scientific community. Both in content and in volume, studies on environmental change have exceeded the reach of previous studies done on seasonal and geological variations. We now have journals focussing exclusively on global change and the effects it has on us and our ecosystems (e.g., Global Environmental Change, Climate Research and Global Change Biology), and others that research strategies to better protect our environment (e.g., Environmental Management, Natural Hazards and Environmental Science and Policy), in addition to special issues like this one focussing exclusively on adaptation and extinction. Many of these journals study change across large and complex contexts, often entire ecosystems, or even the global climate system. This is a complicated mission, and it is no surprise that most of these journals strongly advocate an integration between different scientific fields in order to pool their knowledge and understanding of fundamental natural processes $[9,15]$.

Where scientists from many different backgrounds meet, it is especially important to be clear in our language and concepts [16]. Currently, many papers detail adaptive responses to a particular environmental change, without a clear framework of what exactly is meant with change, which relevant elements in the environment of their species of interest are changing, how fast, or to what extent. Change is most carefully defined in the field of climate change, in which case the definition generally serves as a guide to researchers as to which environmental changes to consider "climate change" and which to consider natural fluctuations [17]. The lack of structure in our understanding of what comprises change limits our ability to estimate the various natural and human-induced forces that exert pressures on animals, and makes it difficult to analyse the many different interactions between such forces. It also causes unnecessary confusion, for instance, when papers seemingly discuss a 
similar topic, but are working on different aspects of change. Finally, it constrains our ability to predict animal adaptive behaviours in response to environmental change.

In this paper, we suggest that in order to understand and predict animals' adaptive response to change, a clearer understanding of change and its attributes is fundamental. We formulate a practical definition that can be applied across fields, and propose a conceptual framework that allows us to distinguish between event- and individual-related attributes of change, estimate which are key influences in each situation, and predict which type of adaptive response will be likely. In this paper, in-depth discussion of concepts and theories has occasionally been sacrificed in favour of the broad focus needed for a meta-level framework that transcends specialised scientific niches.

We are clearly not the first to attempt to categorise different types of environmental change. Turner et al. [18] differentiated between changes that happen on a global level vs. those happening on a regional level. Hendry et al. [13] described how the abruptness and anthropogenic origin of a change affects the plastic response of animals. Sih et al. [9] approached the matter by listing five different types of human-induced rapid environmental change: habitat loss, the spread of exotic species, harvesting by humans, various pollutants and climate change, while mentioning that spatial scale, rapidity and evolutionary novelty contribute to making environmental change a complex and multi-dimensional process. The important difference between previous approaches and the framework proposed in this paper is that we distinguish different types of change based on the fundamental way in which events affect individual animals, and as such on the underlying principles of chance. Rather than defining change by its results, this allows us to study the results of change from its principal components. Although attributes of change that concern the individual animal, such as magnitude [10] and scale [18] of the change (see Sections 3.1.3 and 3.1.4 respectively), have been studied many times in the past, an inclusive framework has thus far been missing.

\section{Defining the Process of Change}

There are many definitions of "change," and reviewing them would fall outside the scope of this paper. To most scientists, the process of change is mainly, if not exclusively interesting because of the response it incites in natural systems. This response is first given on the level of an individual entity [19], before causing more complicated and interactive patterns [20,21], whether the response be an animal's maladaptive breeding strategy, a population's struggle with habitat fragmentation, a species' extinction, or an ecosystem's decline. It is by taking the individual and its state at the moment of the event into the equation that we will gain a better framework from which to consider, manage and ultimately predict animals' (mal)adaptive responses to change [22].

For that reason, we offer the following definition: "Change is a process, consisting of specific attributes, in which an event affects an individual's position in relation to its physical or social surroundings in a way that differs from the established situation". With this definition, we take our understanding of "change" from an event to an interaction between a physical occurrence and an individual's state.

Although for practical reasons, most scientists will be particularly interested in radical, rapid or novel change [9], it will be useful to also include well-known changes like seasonality and habitat fragmentation when considering the process of change. Regular, predictable changes operate on a 
fundamentally similar level as radical or novel changes, with the distinction that for the latter, one or more attributes of change have extreme values and have fallen outside the individual's ability to respond adaptively. As animals' responses to seasonality and other common environmental changes are generally well studied, non-radical change will serve as a model to better understand the interactions between event and individual in more radical environmental changes, and provide insight as to which attribute of change endangered species are struggling with. Therefore, our definition of "change" is intentionally wide. It includes many currently relevant situations, ranging from the impact of agricultural practices, to epigenetic effects on complex behavioural traits, up to and including social attitudes and life history decisions. Situations like hormone balances and changes inside the individual's body are not included in this definition, as it falls below our level of study: the individual and its surroundings.

Before we can apply this definition to our understanding of the process of chance, it requires boundaries as to which time span we are considering, and which scale. When exactly does "change" begin? When does it stop? Many natural processes are gradual and fluctuating, without clear-cut start and end points. The gradual increase of the planet's average temperature may affect ecosystems in the long run, but to a small animal with a lifespan of three months, a single cold winter will be much more devastating [23]. From our definition as stated above, it logically follows that the temporal boundary has to be the individual's lifetime - if an individual's surroundings have not changed from a previous situation within that individual's life, from their perspective, nothing has changed. Similarly, the spatial boundary should be the individual's habitat.

\section{Unravelling Attributes of Change}

When we consider change as a process in which an event affects an individual, we can identify attributes - traits that go with every change - that contribute to the type and severity of the response an individual gives, when an event in their environment forces them to adapt. Below, we consider nine key attributes of change, within which we make a distinction between: (1) event-related attributes, and (2) individual-related attributes. All attributes are defined in relation to previous environmental conditions and act on the level of the individual, within the lifetime and habitat of the individual. Table 1 gives a simple overview of the nine attributes, and illustrates with three examples how detailing these attributes allows us to see the fundamental differences between types of environmental change.

We would like to stress that our purpose in presenting this new perspective on the process of change is not to quantify different attributes and assign values to levels of change, but rather to qualify relevant areas of comparison. In doing so, we aim to facilitate multi-disciplinary communication, and to begin discussing the process of change on a more fundamental and mechanistic level than has so far been the case. In this way, we will be able to better predict, explain and interpret the response of our individuals of interest, as discussed in Section 4 and Table 2 of this paper. 
Table 1. Nine attributes of change; with an example of three types of environmental change on Californian song birds (Passeriformes). This example shows how detailing the event- and individual-related attributes of change can bring clarity into the adaptive pressures animals face from different environmental events.

\begin{tabular}{|c|c|c|c|c|}
\hline & & $\begin{array}{c}\text { Forest fire } \\
{[24]} \\
\end{array}$ & $\begin{array}{c}\text { Urban } \\
\text { noise [25] }\end{array}$ & $\begin{array}{c}\text { Climate } \\
\text { change [26] }\end{array}$ \\
\hline \multicolumn{5}{|c|}{ Event-related attributes } \\
\hline Onset & Does the event come on rapidly or gradually? & rapid & gradual & gradual \\
\hline Duration & $\begin{array}{l}\text { Is the event a temporary occurrence or a lasting } \\
\text { influence? }\end{array}$ & temporary & lasting & lasting \\
\hline Magnitude & What is the strength of the event? & great & great & small \\
\hline Scale & Does the event affect a large portion of the territory? & yes & no & yes \\
\hline Novelty & Has the event occurred often in the individual's past? & yes & no & yes \\
\hline \multicolumn{5}{|c|}{ Individual-related attributes } \\
\hline Perception & Can the individual perceive the event? & yes & yes & no \\
\hline Predictability & Is the individual capable of predicting the event? & no & yes & some \\
\hline Tolerance & $\begin{array}{l}\text { Does the event fall within the individual's tolerance } \\
\text { levels? }\end{array}$ & no & yes & yes \\
\hline $\begin{array}{l}\text { Selective } \\
\text { direction }\end{array}$ & $\begin{array}{l}\text { Does the event call for a response in the same } \\
\text { direction as the individual is moving towards? }\end{array}$ & no & yes & no \\
\hline
\end{tabular}

Table 2. An overview of several behavioural, physical and generational adaptive responses available to individuals when faced with environmental change, and suggestions for event and individual attributes that are predictive and counter-predictive of these responses.

\begin{tabular}{|c|c|c|c|c|c|c|}
\hline \multirow[t]{2}{*}{ Level } & \multirow[t]{2}{*}{ Mechanism } & \multirow[t]{2}{*}{ Response } & \multicolumn{2}{|c|}{ Predictive attributes } & \multicolumn{2}{|c|}{$\begin{array}{c}\text { Counter-predictive } \\
\text { attributes }\end{array}$} \\
\hline & & & Event & Individual & Event & Individual \\
\hline \multirow{4}{*}{ Behavioural } & Relocation & $\begin{array}{l}\text { Individuals (temporarily) relocate } \\
\text { to a better habitat }\end{array}$ & $\begin{array}{l}\text { Large } \\
\text { magnitude }\end{array}$ & $\begin{array}{l}\text { Low } \\
\text { tolerance }\end{array}$ & Large scale & $\begin{array}{l}\text { Low } \\
\text { perception }\end{array}$ \\
\hline & $\begin{array}{l}\text { Conditional } \\
\text { strategies }\end{array}$ & $\begin{array}{l}\text { Individuals flexibly use distinct } \\
\text { canalised behaviours }\end{array}$ & $\begin{array}{l}\text { Long } \\
\text { duration }\end{array}$ & $\begin{array}{l}\text { High } \\
\text { prediction }\end{array}$ & $\begin{array}{l}\text { High } \\
\text { novelty }\end{array}$ & $\begin{array}{l}\text { Low } \\
\text { perception }\end{array}$ \\
\hline & $\begin{array}{l}\text { Behavioural } \\
\text { plasticity }\end{array}$ & $\begin{array}{l}\text { Individuals flexibly choose } \\
\text { appropriate behaviours }\end{array}$ & High novelty & $\begin{array}{l}\text { Low } \\
\text { prediction }\end{array}$ & $\begin{array}{l}\text { Low } \\
\text { perception }\end{array}$ & $\begin{array}{l}\text { Low } \\
\text { tolerance }\end{array}$ \\
\hline & $\begin{array}{l}\text { Ecosystem } \\
\text { engineering }\end{array}$ & $\begin{array}{l}\text { Individuals change their } \\
\text { environment to better suit their } \\
\text { needs }\end{array}$ & $\begin{array}{l}\text { Long } \\
\text { duration }\end{array}$ & $\begin{array}{l}\text { Similar } \\
\text { direction }\end{array}$ & $\begin{array}{c}\text { Short } \\
\text { duration }\end{array}$ & $\begin{array}{l}\text { Opposing } \\
\text { direction }\end{array}$ \\
\hline \multirow{2}{*}{ Physical } & $\begin{array}{l}\text { Developmental } \\
\text { plasticity }\end{array}$ & $\begin{array}{l}\text { Juveniles adjust life history } \\
\text { choices to develop more } \\
\text { adaptively }\end{array}$ & $\begin{array}{l}\text { Long } \\
\text { duration }\end{array}$ & $\begin{array}{l}\text { Similar } \\
\text { direction }\end{array}$ & Fast onset & $\begin{array}{l}\text { Low } \\
\text { tolerance }\end{array}$ \\
\hline & $\begin{array}{l}\text { Morphological } \\
\text { plasticity }\end{array}$ & $\begin{array}{l}\text { Individuals adjust physiological } \\
\text { traits to better survive }\end{array}$ & High novelty & $\begin{array}{l}\text { Low } \\
\text { tolerance }\end{array}$ & $\begin{array}{l}\text { High } \\
\text { novelty }\end{array}$ & $\begin{array}{l}\text { Opposing } \\
\text { direction }\end{array}$ \\
\hline \multirow{2}{*}{ Generationa } & Maternal effects & $\begin{array}{l}\text { Mothers affect offspring } \\
\text { physiology during ontogeny }\end{array}$ & $\begin{array}{l}\text { Long } \\
\text { duration }\end{array}$ & $\begin{array}{l}\text { Similar } \\
\text { direction }\end{array}$ & $\begin{array}{l}\text { High } \\
\text { novelty }\end{array}$ & $\begin{array}{l}\text { Low } \\
\text { prediction }\end{array}$ \\
\hline & $\begin{array}{l}\text { Conditional } \\
\text { reproduction }\end{array}$ & $\begin{array}{l}\text { Individuals adjust reproductive } \\
\text { effort or mate choice }\end{array}$ & $\begin{array}{l}\text { Long } \\
\text { duration }\end{array}$ & $\begin{array}{l}\text { Similar } \\
\text { direction }\end{array}$ & Fast onset & $\begin{array}{l}\text { Low } \\
\text { tolerance }\end{array}$ \\
\hline
\end{tabular}




\subsection{Event-Related Attributes}

Event-related attributes describe the nature of environmental circumstances that affect an individual. We consider three attributes that are often studied in other publications (onset, scale and novelty [9] and two that are relevant but are often overlooked (duration and magnitude).

\subsubsection{Onset}

Sometimes change happens slowly, in very gradual intervals over a long period of time. An example of this is the rising of the sea level [27]. In other cases, change happens rapidly, from one day to the next, or sometimes even from one hour to the next. Although slow environmental changes can have significant long-term effects on ecosystems, events with a rapid onset are more difficult for an individual to deal with, as it provides little time for animals to respond adaptively. Especially when considering an animals' ability to respond to rapid onset, it is important to examine timescales relative to the lifespan of the individual. For example, if a habitat gets fragmented over a span of thousands of years through plate tectonics, animals will experience much less ecological difficulty than if the habitat becomes fragmented in a few months' time by the construction of a highway. Many studies consider rapid change over several decades, which offer important insight into the adaptation of ecosystems [28] but neglect to appraise the environmental stressors affecting the individual. Rapid onset is often (though not solely) the case with human-induced events [9], and at the moment, provides one of the greatest threats to animal and ecosystem conservation. Rapid environmental change has been linked to population extinction [29], especially in species already pressured by other selective forces, or when combined with human-induced change [9].

\subsubsection{Duration}

Next to onset, a relevant event-related attribute is the duration of the event, its permanence. If an event only influences an individual for a very short time, such as a very loud noise, a response might not be required to avoid fitness costs. In other cases, a temporary response is often adaptive-for example hiding in a cave on a day of extremely high temperatures or migrating in winter [30]. If the event influences the individual for a longer time period, a more structural response to the new circumstance is often necessary, as for example happens when animals moult during winter [8], or go into hibernation. Unless the event will continue to influence the environment for a significant part of the individual's lifespan, however, there is little payoff to such an adaptation becoming permanent. Although some events (see Section 3.2.3. Tolerance) need to be responded to immediately regardless of their duration, not all environmental events are of this nature, and as such, the duration of an event becomes an important aspect when understanding and predicting animals' adaptive response.

\subsubsection{Magnitude}

Although the magnitude (also called severity, amplitude, or extremity) of an event is undeniably relevant to an animal's response - and clearly a more extreme event, such as a 10-degree increase in temperature in spring, has a greater and more immediate effect than a minor event, such as a 0.1 -degree increase in temperature in spring-it is difficult to describe how the magnitude of an event 
affects an individual. The reason is that the magnitude of any event is tightly linked to the tolerance level of the individual (see Section 3.2.3. Individual-Related Attributes). Perhaps the most functional way to define the magnitude of an event is "amplitude relative to the range of values the individual is likely to encounter in its normal environment," mirroring the World Meteorological Organisation's approach of a climatic normal [31]. Practically, this would translate into looking at ratios between the magnitude of the event of interest compared to the average magnitude the individual experienced over its lifetime. Clearly defining magnitude is especially useful in multi-disciplinary scientific communication, where events with a large magnitude - and, by extension, animals' response to them — often get confused with events with a large scale (see Section 3.1.4) or a great novelty (see Section 3.1.5).

\subsubsection{Scale}

Even with the previously mentioned attributes being equal, an individual will respond to a large-scale event like a volcano eruption differently than to a small-scale event like a camp fire, and it will even respond differently to changes on a global scale [1]. More than the other event-related attributes, how we consider scale in each situation is highly relative to the size of the individual and especially its habitat, as its habitat affects its immediate survival, as well as future foraging ability, mate availability, and predation pressures [32]. For example, to a small ground-dwelling beetle, a large camp fire may represent a nearly identical event as a forest fire. Whereas this adds a measure of subjectivity to the concept, it also prevents us from accidentally considering scale from a human perspective, and only labelling events as "large scale" when they are such to us. The larger the scale of an event, relative to the individual's habitat, the higher the chance that trophic interactions between the individual and its predators and prey are also affected [33].

\subsubsection{Novelty}

Perhaps the most radical changes that animals have to cope with is the introduction of novel events that individuals have no experience with in their evolutionary history, and so they have no pre-programmed response to the event, or even a personal and thus learned response to it. Novelty in this context is defined as novel to the individual within its lifetime. Most commonly, animals respond to unfamiliar situations first and foremost with a stress response [34,35]. Novelty is especially interesting in cases where the event requires a specific adaptation that cannot be covered with a standard response. Oil spills are a good example. Other events with high novelty are the artificial noise levels in cities, which especially vocal animals such as birds are forced to adapt to [36]. Most events with high novelty, unsurprisingly, are human-induced.

\subsection{Individual-Related Attributes}

Individuals may respond to similar changes in their environment in different ways [37]. An event may be completely novel, affect a large scale and have a very immediate onset, such as the deforestation of a natural area for commercial projects. However, if the individual is not dependent on the circumstance that is changing, or if it falls well within tolerance levels (say, the individual has a huge habitat, which this area is only a small part of), it will not experience much of a change in its 
environment. How heavily an individual is impacted by an event happening in its surroundings and how it is likely to respond depend largely on the state and history of the individual. The shape of the vulnerability of an individual to environmental change depends on the individual-related attributes of change [37]. We consider four attributes that depend on the individual rather than on the event: perception, prediction, tolerance and direction.

\subsubsection{Perception}

Individuals need to perceive changes (in rainfall, predation pressure, daylight, habitat size or otherwise) on some level in order to respond to a change, whether that perception be conscious or instinctive [38]. Animals have many sensors that give them vital information about their surroundings, most of which are processed directly by the autonomic nervous system, which gives a very fast and coordinated response that aims to minimise the net cost to the individual [39]. Through a multitude of cues, including chemical [40] or auditory cues [41,42] animals track their environment to find partners, food, or natural enemies. In order to track their environment effectively, individuals need to invest time into monitoring their surroundings, and they must do so thoroughly enough that they do not miss any relevant events. Even a lag in tracking a changing environment [43] may be costly to an individual. If an individual fails to perceive an environmental event, misperceives or mistranslates it, their response will be mismatched or non-existent. Human-induced pollution of air, water or the chemical environment, can distort the cues that animals rely on, and in doing so limit individuals' ability to respond effectively [40,41]. For example, fish responses to chemical alarm cues, which elicit anti-predator behaviour in conspecifics, are affected by both light levels and visibility in the water [44].

\subsubsection{Prediction}

Although the debate whether animals use prospective cognition (future-thinking) to predict events is still ongoing [45], most animals can, to a certain degree, predict reoccurring events in their surroundings and how these events are going to impact them, through a long evolutionary history of adaptation and through processes of learning earlier in life. A clear example is the winter migration of certain bird species, which is tuned to ecological conditions [46]. In addition to predicting a recurring event like seasonality [4], individuals may use environmental cues to predict the duration of an event, or the quality of a habitat, which allows them to respond adaptively, often even before the event occurs [47]. When these predictions are no longer accurate, due to shifts in food peaks or changes in weather patterns, the behaviours that were adaptive during many species' evolutionary history can become a problem $[33,48]$. In addition, animals' inability to predict events increases their stress response, and as such lowers their overall health [49]. Since predictability of environmental events is limited not only to the frequency and regularity of the events, but also to the cognitive abilities and experience of the individual, prediction affects whether and how an individual might respond, and as such can be considered a relevant attribute of the process of change. 


\subsubsection{Tolerance}

Not all environmental factors are equally important to an individual. For an animal that forages on multiple prey, the loss of a prey species that constitutes only a small percentage of their energy intake will not affect them as strongly as losing their main food group. Tolerance, which is closely related to the well-studied concept of vulnerability [17,50,51], can be defined as "the capacity of enduring or resisting the action." It indicates how much physical or social stress the individual can withstand before suffering serious consequences, what its biological limits are, and at which point responding to an event becomes urgent for survival. Separate from other attributes of change, this concept has been the focus of much practical as well as theoretical work [52]. While an individual's specific tolerance to withstand an environmental event depends on their physiology and life history, it is to be expected that animals will be especially dependent on basic needs such as food supply, temperature, and safety. Tolerance levels are not fixed for each individual, but rather depend on the individual's state, and can be increased through various adaptive responses (see Section 4). Tolerance is an important attribute, especially when studying species who already live near their physiological limits and as such lack adaptive capacity $[2,53]$.

\subsubsection{Selective Direction}

Direction considers to what extent the individual is capable of responding to the event, both evolutionary and mechanistically, in the face of other selective forces and environmental demands that currently affect it, and to what extent such forces prevent the individual from responding to the event most optimally. If environmental change occurs in too many dimensions simultaneously, it cannot be tracked by adaptation. Although the selective direction of an individual experiencing environmental change is often overlooked, this attribute can explain why individuals do not respond to changes as expected based on existing theory. A beautiful example concerns British butterflies, whose populations were found to decline when faced with climate warming, despite expectations that they would do well, due to dual selective forces of habitat modification and climate warming [54]. Since it requires some understanding of other selective pressures working on the individual, selective direction of the event is often difficult to measure concretely. As environmental pressures are changeable in their own right, an individual's selective direction can best be considered similar in principle to an individual's state (such as level of hunger): it is the adaptive direction the individual is moving towards due to its environmental conditions. If the event requires the individual to move in a direction opposite to other selective forces it experiences, it will suffer negative fitness consequences - either it adapts badly to the new event, or it runs into problems with other selective forces. By focussing outside the costs and benefits of a phenotype in only a single dimension, we may prevent the likelihood of phenotypeenvironment mismatches [55], and avoid mistakes in predicting to what extent an individual is pushed to respond to environmental events [56]. An example is the effect of increase in spring temperature on certain migratory bird species: while the increase in itself falls easily within the birds' tolerance levels, it pushes them to arrive at their breeding grounds earlier, which affects food availability, breeding conditions and nestling survival [57]. 


\subsection{Interactions}

The nine attributes as described above are distinct forces that can be separately estimated and studied. However, it is the interaction within and between event- and individual-related attributes that characterise the impact a change in environment will have on an individual, and how the individual is likely to respond. Table 1 illustrates at the hand of three examples how considering the attributes of change and the interactions between them make a forest fire, urban noise, and climate change fundamentally different changes to a Californian song bird. It shows that, especially as far as individual-related attributes are concerned, a forest fire and urban noise represent fundamentally different events. The similarity in magnitude and perception is expected, since events with greater magnitude with regards to an individual are generally easier to perceive by them. Table 1 also shows that perhaps one of the bigger problems with climate change is the fact that animals cannot clearly perceive it, which in interaction with its lasting duration results in adaptive difficulty.

Some specific event properties and individual properties seem inherently linked. Environmental effects that have either a rapid onset or a high novelty will likely be difficult to predict, although there will be exceptions. Individuals who are not very dependent on an environmental circumstance may have a high tolerance to its changing, but the opposite is not necessarily true. In certain cases, even if an event happens for a very short time interval, the effect on an individual may be vast: a good example again are oil spills. Finally, there are cases where one attribute overrides other attributes. If an individual has a very low tolerance for change in an environmental factor, such as a chemical spill, it will respond regardless of magnitude, duration, scale or novelty of the event.

From this framework, we can distil some general attributes which are especially of concern to animal adaptation. The most vulnerable individuals will be those faced with an interplay of attributes.

It is no surprise that adaptation becomes more difficult when multiple event attributes exert adaptive pressure on an individual, as we already referred to in the individual attribute. "selective direction." Synergistic feedbacks, in which simultaneous actions of separate processes have a greater effect than the sum of its effects, may make species extremely vulnerable to environmental events [37] (reviewed in [58]). Many human-induced changes to the environment fall into this category $[59,60]$, as they tend to have both a rapid onset, a high amount of evolutionary novelty and affect a large scale. Please see the forest, urban noise and climate change examples from Table 1.

\section{Consequences for the Adaptive Response}

When considering the sheer amount of events that happen in an animal's life on a daily basis, it becomes clear that individuals need to prioritise which events to respond to, in what manner, and to what extent. A long research history has shown that there are a select number of strategies animals use when confronted with a changing environment [7,14,15,39,52,61-65], all of which come with their own costs and advantages. The extent to which such strategies are available and/or adaptive to individual animals depends first of all on its species' characteristics and its particular evolutionary constraints, and, secondly, on the event and individual attributes of the change.

In the following section, we consider how individual and event attributes affect key animal responses to change on a behavioural, physiological and generational level. Behavioural responses 
involve evading or mediating unfavourable conditions; physiological responses involve dealing with the environment by adjusting morphologically and generational responses involve direct effects on the next generation through the offspring [66]. It is clearly possible for multiple adaptive responses to be employed at the same time [65]. We emphasise that an animal's response to a particular situation will most often not be a conscious choice, but rather an unconscious instinctual or hardwired response motivated by internal processes. As such, conscious awareness (or perception) of the environmental circumstance is equally not required in order to respond to environmental situations. We discuss the adaptive value of such choices, conscious or otherwise, in relation to the event and individual attributes of change as detailed above. Table 2 gives a brief overview of these key adaptive responses, and the extent to which they may be predicted by event and individual attributes.

\subsection{Behavioural Responses}

Behaviour mediates interactions between an individual and its environment $[9,14]$. An individual's immediate success or failure in a modified environment is determined by its behaviour, and so it is no surprise that changing one's behaviour is often the fastest, least costly and most effective way to respond. In addition to being adaptive, short-term, flexible behavioural responses can provide species with more time to develop physiological and evolutionary adaptations [14]. As behavioural responses depend on the genetically determined reaction norms [67], individuals are limited in the behavioural mechanisms available by their species evolutionary history.

\subsubsection{Relocation}

Individuals may avoid events in their environment entirely, and relocate, either temporarily through migration, or permanently through dispersal. Migrating animals move directionally, undistracted by resources that would usually halt it, with distinct departing and arriving behaviours [68]. Many bird species migrate sometimes across continents, in order to breed at food-abundant sites, and then winter in warmer locations [69]. Dispersing animals move from their original habitat and settle in a different location with more favourable circumstances, without returning [70]. Although empirical tests of the adaptive value of different dispersal strategies are rare [71], dispersal followed by reproductive isolation with the source population is well known as a speciation [72].

Relocation is not possible when migration routes are cut off, or the individual lacks sufficient mobility. When the current location is very profitable or when individuals have a high fidelity to their territory [73], relocation is less likely to occur. Aside from species-specific characteristics, the costs and benefits of relocation are generally determined by the scale of the event [74]. When individuals do relocate, other adaptive strategies often follow, as the new location rarely has all the same conditions as the old. Relocation as an adaptive strategy is especially useful with events with a rapid onset [30] or great magnitude, or with individuals with a very low tolerance. For many animal species, relocation has been made more difficult by habitat fragmentation [75] and changes in predictability of yearly events [33]. As such, conservationists may opt for translocation of endangered species. However, translocation failure is common [70], and success stories are rare [76]. 


\subsubsection{Conditional Strategies}

Conditional strategies is a term for a set of canalised behaviours, through which animals of a particular species do A in situation 1, and B in situation 2, or do either A or B in any given situation. A classical example involves Sinervo's lizards [77], where males have three strategies available to them, which they may use depending on the situation. Conditional behaviours can be hardwired in the genetics, and do not require any level of plasticity on the side of the individual. Through the use of conditional strategies, often evolved over many generations, animals can give specific behavioural responses depending on their physiological or social status or the environmental cues they perceive [78]. This allows them to remain relatively flexible, while still displaying canalised behaviours that are targeted to the situation at hand [79]. With this type of response, the behavioural strategies are already part of the individual's genetic coding, and by extension of their social dynamics. This makes the use of conditional strategies very effective with predictable fluctuations in environmental conditions, even if these have a large magnitude, yet cause trouble in cases where the individual cannot accurately perceive the environmental cues they rely on.

\subsubsection{Behavioural Plasticity}

Unlike conditional strategies, behavioural plasticity is generally not hardwired. At the individual level, (phenol-typic) plasticity is usually quantified by the degree to which the same genotype may give rise to different phenotypes under different conditions. As animals use environmental cues to respond with adjustable behaviours not pre-determined by their evolutionary past [80], behavioural plasticity allows for a more tailored response to the current circumstances the animal is experiencing. For example, shore birds adjust the size of their gizzard (stomach) in response to the shell-to-flesh ratio of their bivalve prey [81]. It has often been studied hand in hand with behavioural syndromes as a method for individuals to respond more flexibly [82]. However, plasticity also comes at a general cost while its benefits are often small and frequency dependent [83]. The usefulness of behavioural plasticity to individuals is especially dependent on accurate perception of environmental cues, as making an inappropriate choice, or not responding fast enough, can potentially lead to death [80]. Although in itself, behavioural plasticity is neither adaptive nor maladaptive [56], it is one perhaps the mechanism that allows for the most flexibility and adaptive freedom when faced with circumstances that individuals have never encountered before, as it has been shown to allow for a short-term adjustment to novel environments [84].

\subsubsection{Ecosystem Engineering}

Individuals of some species have the ability to change their environment, rather than (just) change themselves: they are ecosystem engineers. Clear examples are termite mounds [85], a bird species called the European bee-eater [86], and, of course, our own human species. Ecosystem engineers may affect surrounding animal species, as well as entire ecosystems [87]. This response, while useful in response to events with a slow onset and long duration, will be difficult to sustain when events happen rapidly, last only shortly, or have a large magnitude. 


\subsection{Physiological Responses}

In changing environments, modifying the physical body can be an effective and relatively fast adaptive response, which can be done permanently through developmental plasticity [88], by, for example, increasing growth rate as juveniles to escape predation [38] or temporarily, like we know from a chameleon changing its colours [89] and from birds going into moult [8]. We will discuss both physiological responses below.

\subsubsection{Developmental Plasticity}

In many species, juveniles, or sometimes even embryos, adjust their physiological development to the environment they were born into [90]. For example, the young of certain species of lizard [91] and bird [90] use environmental cues to time their hatching date and even size to favourable circumstances. Developmental plasticity can lead to a better match between adult phenotype and the selective environment [92,93], especially in cases where environmental conditions during ontogeny match those later in life. Through developmental plasticity, young animals may change their tolerance levels to unfavourable environmental conditions, sometimes at the cost of other traits.

\subsubsection{Morphological Plasticity}

Morphological plasticity is the phenomenon of a genotype producing different phenotypes in response to different environmental conditions [56,94]. It is similar to behavioural plasticity, yet tends to involve longer-term modifications (lasting for an entire season, or a lifetime). Physiological responses can be remarkably fast $[13,95]$. For example, shore birds adjust the size of their gizzard in response to the shell-to-flesh ratio of their bivalve prey [81]. Physiological responses can be especially useful when the event's magnitude is large enough that a strictly behavioural response would be inadequate, when the event is predictable and when the event happens across a very large scale. Morphological plasticity can cause populations to persist in the face of environmental change, and reduce the strength of selection [96,97].

\subsection{Generational Responses}

As the scope of this paper is limited to individual-level responses, we consider generational responses only to the extent where individuals, passively or actively, affect the generation after them. By understanding the individuals' response to change, we can also better estimate how the next generation will be affected. Generational responses in this context include any adaptive response given by the individual that carries across the individual's lifespan to its offspring, thereby allowing adaptation to happen over much longer timescales. In species where there are no overlapping generations, the young will either perceive their environment early in life and adapt accordingly, or be affected by hormonal influences from the previous generation as early as during conception, or both. The first is a case of developmental plasticity, and all the literature concerning developmental plasticity applies most prominently. The second is a case of maternal effects, as detailed in the section below. Generational responses can be adaptive when events have a sufficiently long duration, and when selective pressures of the event do not conflict with pressures exerted by other evolutionary 
forces. While generational responses to human-induced environmental change are possible and do happen [98], they often do not work effectively or fast enough to avoid species extinction [2].

\subsubsection{Maternal Effects}

Maternal effects can be defined many ways, but most commonly are considered as the direct effect of a mothers' phenotype on that of her offspring [99]. Often, hormonal or nutritional effects get passed down passively to the next generation based on the mother's state during gestation [100]. As a result, effects are not by default adaptive, and can even be counter-adaptive when environments change strongly within the individual's lifespan $[101,102]$. However, maternal effects can also be a powerful source of cross-generational adaptation to a predictable environment [100,103], capable of tracking the environment better and faster than genetic adaptation [104]. For example, maternal manipulation of vitamin E in egg yolk increases arrival times in bird migration [98]. Maternal effects are often studied in relation to the individual-attribute prediction $[105,106]$. When the individual cannot accurately predict the environment their offspring will experience, mothers may increase within-clutch variation in offspring phenotype (bet-hedge) [105]. It is possible for maternal effects to facilitate phenotypic evolution, although it is still unclear under which circumstances this is likely to be the case [107].

\subsubsection{Conditional Reproduction}

Conditional reproduction in this context refers to reproductive strategies used by animals when faced with changing environments. Although reproductive success is how biologists measure fitness, reproducing can be very costly to individuals. Depending on the species, reproduction can involve an investment of resources, an investment in sexual displays, time spent searching for a suitable mate and/or fighting for access to a mate, and parental investment in the resulting offspring. As a result, individuals across many species of animal opt not to reproduce in difficult years, or reproduce much fewer offspring. Similarly, they may choose to reproduce much later in life, which can have far-reaching effects on population demographics. In species where there is active mate choice, females confronted with a changed environment may choose males who are doing better under the new circumstances, or instead may be confused by suddenly mismatched sexual signals [108]. In this way, conditional reproduction is a way for individuals to pass on better genes to the next generation. Conditional reproduction is a precursor to natural selection.

\subsubsection{Natural Selection}

The ability of evolutionary processes to keep up with the rapidity and wide scale of human-induced change has been a concern to scientists from many different fields [63]. Whereas natural selection does not fit directly into this framework - as it is not an individual-level response but rather a natural process in its own right-for completion, we discuss briefly how the responses described above may interface with natural selection processes. In addition to small population size, slow reproduction [10], a high degree of habitat specialisation, and high edge sensitivity [12], genetic adaptation may be limited by lifespan, as long-living species tend to be faced with many more environmental changes within a lifespan than short-living species. With an increased number of events comes also the risk that 
the events the individual experiences work in different selective directions, making especially genetic adaptation even more unlikely. Although there are cases in which evolutionary adaptation can be rapid [2], rapidity in such cases still involves many generations. Given this, we should expect to see more generational responses in short-living species, and more behavioural and physiological responses in longer-living species.

\section{Practical Applications}

In this paper, we offered a conceptual framework from which to consider the process of environmental change and the individual's ability to adapt to it, with the purpose to facilitate multi-disciplinary communication, to begin discussing the process of change on a more fundamental and mechanistic level, and to better predict, explain and interpret the response of our individuals of interest, as discussed in Section 4 and Table 2 of this paper. We will discuss practical applications for each of these aims separately.

\subsection{Facilitating Communication}

A vast number of papers are being published yearly on the topic of environmental change and its related areas (extinction, resilience, adaptive ability, global warming), by researchers from a wide variety of fields. As most of us specialise in a scientific niche, and often with a very specific model species, the full scope of these innovations and new empirical evidence can be difficult to oversee. When papers detail the attributes of change under review, finding relevant material and relating it to one's own studies becomes easy. Even when papers do not specifically state event and individual attributes of change, but clearly describe the focal type of change, the content of such papers can still be placed within this framework, and as such related to similar studies.

By characterising the attributes of change in a paper, one can quickly see the fundamental differences between two similar-looking papers, and choose the one most specific to one's interest. An article starting with "Adaptation to a sudden extreme change in environment [...] is analysed" [62] is addressing both event attributes of rapid onset and high magnitude, while an article whose opening line is "This article addresses the nature and challenge of adaptation in the context of global climate change" is instead considering events with a more gradual onset, a long duration, and a relatively small magnitude [109]. While both articles on the surface seem to be deal with adaptation to human-induced events, a closer study of the attributes they focus on show that they are studying very different changes, and as such will be dealing with very different adaptive responses.

\subsection{Clearer Analysis of Change}

When studying the adaptive ability of animals to a certain expected change, it is often necessary to first make a characterization of the initial state of the focal system, including assessment of genetic diversity, trait plasticity, system functions, etc. With the use of event and individual attributes of change, it becomes possible to index relevant traits of the animal under study, and get a comprehensive idea of the initial state of the system, as shown in our case study (Section 6). When the expected change is indexed similarly and event attributes are matched up with individual attributes, areas of 
vulnerability will become apparent more easily. For example, if one wants to know why barn swallows are having difficulty adjusting their migration times [46], this framework allows one to take inventory of the event- and individual-related attributes (large scale, low perception, see Table 2) and give a well-founded analysis of the different and sometimes perhaps counter-acting selective pressures affecting the individuals of this species, and, by extension, the larger-level patterns.

The attributes of change we described may also be used to design more targeted experiments. In this case, it is not necessary to identify (concrete measures for) each and every attribute for the event of interest. It may be sufficient to identify the one or two attributes that most strongly influence the individual's response, and use these to better understand, predict and then test the individual's consequent behaviour. Within experimental designs, this framework may help scientists to understand why the patterns they find in laboratory studies do not always match those observed in nature: for example, considering the individual attribute tolerance shows the importance of choosing experimental parameters that fall within the levels that individuals are likely to encounter in nature. If experiments use stimuli with an extreme magnitude in order to ensure a measurable response, animals may not be able to respond effectively, or will respond with a different adaptive mechanism than they would to a more realistic stimulus.

\subsection{Predicting and Interpreting Responses}

By separating event-related attributes from individual-related attributes, it becomes possible to study what effect a specific past event had on an animal species, as well as to predict how future human-induced events may affect different key species in the surrounding nature. The presence of endocrine disruptors, such as DDT, pose a serious threat to many animals [110]. These can be considered as an event against which individuals of many species have a low tolerance, and which affects their perception of environmental events. While the expression of the fitness costs from endocrine disruptors may not be direct (that is, they do not always affect food intake or reproduction), they do have serious adverse effects on behaviour and health. According to Table 2, low tolerance is especially predictive of relocation, where possible, or morphological plasticity. As the occurrence of DDT is a widespread and difficult-to-perceive event, relocation as a response is less likely, and one would expect to find mainly morphological plasticity in response. Although much work has been done to show the ecological danger of endocrine disruptors, it is as yet unknown if animals are capable of giving an adaptive response.

Finally, a possible application that will need further work to develop can be found in areas of conservation and responsible planning of human-induced environmental changes. By separating event-related attributes from individual-related attributes, it is possible to study what effect a specific past event had on an animal species, as well as to predict how future human-induced events may affect different key species in the surrounding nature. This opens possibilities for more targeted and well-reasoned conservation strategies, since past experience has shown that not all efforts to mediate environmental change are helpful [61]. For example, species translocation often fails [70]. Such cases can be analysed using the event and individual attributes for the individuals of the species in question, to come to a clearer understanding of the most adaptive responses (see Table 2). 


\section{Case Study}

To illustrate a way in which the framework proposed in this paper may be applied to gain a clearer understanding of the nature of specific environmental changes and animals' subsequent adaptive response to those changes, we detail below a short case study involving the model species Gasterosteus aculeatus, the three-spined stickleback.

The three-spined stickleback is a small fish, perhaps best known for its great potential to plastically adjust both its behaviour and physiology based on its surroundings [111]. Their fast radiation from marine ecosystems to freshwater shows that they also having a potential for fast evolution [112]. Sticklebacks live one to two years under natural circumstances, and are used as a model system in the fields of animal personality [67,110], animal behaviour [113,114], ecology [115], and speciation [112]. For a recent study, we studied the adaptive response sticklebacks are capable of giving in response to minor, natural environmental fluctuations. We empirically tested to what extent the early-life environment affects individual stickleback's ability to give an adaptive behavioural response when foraging in the face of human-induced disturbance. For this, we used twelve small semi-natural ponds with identical starting conditions, which had naturally diversified for a year.

Using the framework proposed in this paper, we first index the event and individual attributes relevant to this system (Table 1). The event we are studying is the natural diversification of twelve ponds over the span of a year, which mainly constituted of an increase in algae density and population size. Whereas the human-induced disturbance can also be considered a change event in its own right, the adaptation we are studying is to the natural diversification. Given the one- to two-year lifespan of sticklebacks, this event has a very gradual onset, its duration is permanent, its magnitude is rather small, its scale is large given that it affects the entire habitat available to the sticklebacks, and the evolutionary novelty of natural diversification is low. The individuals we are studying are three-spined sticklebacks. They are easily able to perceive changes in population and algae density [116], they can predict based on their past experience how their environment is likely to be in the future, and the event falls easily within their tolerance levels. Given the lack of predation and overall neutral status of these populations, we do not expect there to be strong selection pressures opposing adaptation to this event. It seems that the most relevant attributes of change consist of the gradual onset and large scale.

From the previous index, we can estimate which type of adaptive response will likely be relevant (Table 2). Migration is clearly not an option, both due to experimental setup and the specific attributes of change. The use of conditional, environment-dependent strategies, ecosystem engineering, and developmental plasticity seem very likely, and maternal effects seem possible. We do not expect to find much behavioural or morphological plasticity as an adaptive response to this setup.

From the previous indices, we can search the literature specifically for papers with key phrases such as "gradual environmental change," "slow habitat change,"and "developmental plasticity." We can mostly ignore papers regarding "rapid onset," "novelty" and "evolutionary effects of predation" as these study very different attributes of change. From this, we learn that and we find papers entitled "Habitat complexity modulates phenotype expression through developmental plasticity" [117] and "Phenotypic plasticity for life history traits in a stream population" [118]. Such a more targeted search is especially useful with a model species as widely used as the stickleback, in a field as diverse as adaptation to changes in environment. 
We relate our results back to the literature, by discussing empirical work done on developmental processes under slow, low magnitude environmental change. In this, we find literature regarding behavioural differences between populations of sticklebacks [114], and relevant titles like "The effect of behavioural and morphological plasticity on foraging efficiency in the three-spined stickleback" [119]. Given the other adaptive responses that may be relevant according to the framework, we know to discuss the possibility of ecosystem engineering - that is, a bi-directional interaction between the naturally diversifying environment and the stickleback's use of the environment - and the possibility that some of the variation in rearing conditions may be due to maternal effects.

The paper on which this case study is based is currently under review [120].

\section{Conclusions}

This paper offered a definition of change accompanied by a conceptual framework from which to consider key event- and individual-related attributes of change, and the most common adaptive responses given by the individual animal. We considered these attributes from a qualitative rather than a quantitative angle. Although this paper focusses exclusively on animal responses, the same ideas may also be applied to studies of change in plants, humans, or ecosystems at large. In such cases, types of behavioural, physiological and generational responses may have to be adjusted to the system in question.

Future literature study will be needed to index a portion of recent empirical work on environmental change, and to analyse links between attributes of change to determine the most prevalent interactions for vulnerable species. Similarly, empirical studies are needed to accurately match attributes to the available adaptive responses, and to test resilience thresholds before a response is given. In particular, one would like to predict when which type of response can be expected to be predominant and in which way the immediate response to environmental change affects the long-term survival and adaptive capacity of a system. Such an undertaking will require experts from multiple fields sharing their deeper understanding of underlying systems.

The drastic levels of environmental variation that we are currently observing in nature, which cannot be empirically manipulated due to its size and scale, offer an often overlooked yet invaluable opportunity for the fields of evolution and ecology and all the subfields therein to study the intricacies of animal responses and the complicated relationship between the individual, species or ecosystem and its environment on a level that has never before been possible. It is our hope that this conceptual framework will contribute to a clearer communication between scientific fields, and a better understanding of patterns and processes in the natural world.

\section{Acknowledgments}

This research was made possible by the contribution of the Ubbo Emmius grant by the University of Groningen. We are grateful for their support. We would also like to thank an anonymous reviewer for their valuable comments and suggestions. 


\section{Conflict of Interest}

The authors declare no conflict of interest.

\section{References and Notes}

1. Nelson, D.R.; Adger, W.N.; Brown, K. Adaptation to Environmental Change: Contributions of a Resilience Framework. Annu. Rev. Environ. Resour. 2007, 32, 395-419.

2. Hoffmann, A.A.; Sgrò, C.M. Climate change and evolutionary adaptation. Nature 2011, 470, 479-485.

3. Bakker, M.R.; Jolicoeur, E.; Trichet, P.; Augusto, L.; Plassard, C.; Guinberteau, J.; Loustau, D. Adaptation of fine roots to annual fertilization and irrigation in a 13 -year-old Pinus pinaster stand. Tree Physiol. 2009, 29, 229-238.

4. Bradshaw, W.E.; Holzapfel, C.M. Genetic response to rapid climate change: it's seasonal timing that matters. Mol. Ecol.2008, 17, 157-166.

5. Wysujack, K.; Greenberg, L.A.; Bergman, E.; Olsson, I.C. The role of the environment in partial migration: food availability affects the adoption of a migratory tactic in brown trout Salmo trutta. Ecol. Freshw. Fish 2009, 18, 52-59.

6. Robson, A.A.; Leaniz, C.G. D.; Wilson, R.P.; Halsey, L.G. Behavioural adaptations of mussels to varying levels of food availability and predation risk. J. Mollus. Stud. 2010, 76, 348-353.

7. Morris, D.W. Adaptation and habitat selection in the eco-evolutionary process. Proc. R. Soc. B 2011, 278, 2401-2411.

8. Hedenström, A. Adaptations to migration in birds: behavioural strategies, morphology and scaling effects. Phil. Trans. R. Soc. B 2008, 363, 287-299.

9. Sih, A.; Ferrari, M.C.O.; Harris, D.J. Evolution and behavioural responses to human-induced rapid environmental change. Evol. Appl. 2011, 4, 367-387.

10. Bell, G.; Collins, S. Adaptation, extinction and global change. Evol. Appl. 2008, 1, 3-16.

11. Vitousek, P.M. Human Domination of Earth's Ecosystems. Science 1997, 277, 494-499.

12. Meyers, L.A.; Bull, J.J. Fighting change with change: adaptive variation in an uncertain world. Trends Ecol. Evol. 2002, 17, 551-557.

13. Hendry, A.P.; Farrugia, T.J.; Kinnison, M.T. Human influences on rates of phenotypic change in wild animal populations. Mol. Ecol. 2008, 17, 20-29.

14. Tuomainen, U.; Candolin, U. Behavioural responses to human-induced environmental change. Biol. Rev. 2011, 86, 640-657.

15. Raubenheimer, D.; Simpson, S.J.; Tait, A.H. Match and mismatch: conservation physiology, nutritional ecology and the timescales of biological adaptation. Phil. Trans. R. Soc. B 2012, 367, $1628-1646$.

16. O'Brien, K.L.; Eriksen, S.; Schjolden, A.; Nygaard, L. What's in a word? Conflicting interpretations of vulnerability in climate change research. Available online: http://dspace.cigilibrary.org/jspui/handle/123456789/7304/ (accessed on 20November 2012).

17. Ionescu, C.; Klein, R.J. T.; Hinkel, J.; Kumar, K.S.K.; Klein, R. Towards a Formal Framework of Vulnerability to Climate Change. Environ. Model. Assess. 2009, 14, 1-16. 
18. Turner, B.L., II; Kasperson, R.E.; Meyer, W.B.; Dow, K.M.; Golding, D.; Kasperson, J.X.; Mitchell, R.C.; Ratick, S.J. Two types of global environmental change: Definitional and spatialscale issues in their human dimensions. Global Environmen. Change 1990, 1, 14-22.

19. Gardner, A.; Grafen, A. Capturing the superorganism: A formal theory of group adaptation. J. Evol. Biol. 2009, 22, 659-671.

20. Hamilton, W.D. The genetical evolution of social behaviour. I. J. Theor. Biol. 1964, 7, 1-16.

21. Paenke, I.; Jin, Y.; Branke, J. Balancing Population- and Individual-Level Adaptation in Changing Environments. Adapt. Behav. 2009, 17, 153-174.

22. Reed, T.E.; Waples, R.S.; Schindler, D.E.; Hard, J.J.; Kinnison, M.T. Phenotypic plasticity and population viability: the importance of environmental predictability. Proc. R. Soc. B 2010, 277, 3391-3400.

23. Valdesalici, S.; Cellerino, A. Extremely short lifespan in the annual fish Nothobranchius furzeri. Proc. R. Soc. B 2003, 270, S189-S191.

24. Bagne, K.E.; Purcell, K.L. Short-term responses of birds to prescribed fire in fire-suppressed forests of California. J.Wildlife Manage. 2011, 75, 1051-1060.

25. Brumm, H. Animal Communication: City Birds Have Changed Their Tune. Curr. Biol. 2006, 16, R1003-R1004.

26. Both, C.; Bouwhuis, S.; Lessells, C.M.; Visser, M.E. Climate change and population declines in a long-distance migratory bird. Nature 2006, 441, 81-83.

27. Nicholls, R.J.; Cazenave, A. Sea-Level Rise and Its Impact on Coastal Zones. Science 2010, 328, 1517-1520.

28. Hecky, R.E.; Mugidde, R.; Ramlal, P.S.; Talbot, M.R.; Kling, G.W. Multiple stressors cause rapid ecosystem change in Lake Victoria. Freshwater Biol. 2010, 55, 19-42.

29. Bell, G.; Gonzalez, A. Evolutionary rescue can prevent extinction following environmental change. Ecol. Lett. 2009, 12, 942-948.

30. Warner, K.; Hamza, M.; Oliver-Smith, A.; Renaud, F.; Julca, A. Climate change, environmental degradation and migration. Nat. Hazards 2010, 55, 689-715.

31. Knutson, T.R.; McBride, J.L.; Chan, J.; Emanuel, K.; Holland, G.; Landsea, C.; Held, I.; Kossin, J.P.; Srivastava, A.K.; Sugi, M. Tropical cyclones and climate change. Nat. Geosci. 2010, 3, 157-163.

32. Calsbeek, R. Experimental evidence that competition and habitat use shape the individual fitness surface. Journal of Evolutionary Biology 2009, 22, 97-108.

33. Both, C.; Van Asch, M.; Bijlsma, R.G.; van den Burg, A.B.; Visser, M.E. Climate change and unequal phenological changes across four trophic levels: constraints or adaptations? J. Anim. Ecol. 2009, 78, 73-83.

34. Dingemanse, N.J.; Wright, J.; Kazem, A.J. N.; Thomas, D.K.; Hickling, R.; Dawnay, N. Behavioural syndromes differ predictably between 12 populations of three-spined stickleback. J.Anim. Ecol. 2007, 76, 1128-1138.

35. Rothwell, P.E.; Kourrich, S.; Thomas, M.J. Environmental novelty causes stress-like adaptations at nucleus accumbens synapses: Implications for studying addiction-related plasticity. Neuropharmacology 2011, 61, 1152-1159. 
36. Proppe, D.S.; Sturdy, C.B.; St. Clair, C.C. Flexibility in Animal Signals Facilitates Adaptation to Rapidly Changing Environments. PLoS One 2011, 6, e25413.

37. Adger, W.N.; Eakin, H.; Winkels, A. Nested and teleconnected vulnerabilities to environmental change. Front. Ecol. Environ. 2009, 7, 150-157.

38. Bell, A.M.; Dingemanse, N.J.; Hankison, S.J.; Langenhof, M.B.W.; Rollins, K. Early exposure to nonlethal predation risk by size-selective predators increases somatic growth and decreases size at adulthood in threespined sticklebacks. J. Evol. Biol. 2011, 24, 943-953.

39. Fuller, A.; Dawson, T.; Helmuth, B.; Hetem, R.S.; Mitchell, D.; Maloney, S.K. Physiological Mechanisms in Coping with Climate Change. Physiol. Biochem. Zool. 2010, 83, 713-720.

40. Lürling, M.; Scheffer, M. Info-disruption: pollution and the transfer of chemical information between organisms. Trends Ecol. Evol. 2007, 22, 374-379.

41. Swaddle, J.P.; Page, L.C. High levels of environmental noise erode pair preferences in zebra finches: implications for noise pollution. Anim. Behav. 2007, 74, 363-368.

42. Rabin, L.A.; McCowan, B.; Hooper, S.L.; Owings, D.H. Anthropogenic Noise and its Effect on Animal Communication: An Interface Between Comparative Psychology and Conservation Biology. Int. J. Comp. Psych. 2003, 16, 172-192.

43. Waxman, D.; Peck, J.R. Sex and Adaptation in a Changing Environment. Genetics 1999, 153, 1041-1053.

44. Paglianti, A.; Ceccolini, F.; Berti, R. Fright reaction in light and dark: How visual information availability modulates the response to chemical alarm cues. Ethol. Ecol.Evol. 2010, 22, 63-71.

45. Raby, C.S.; Clayton, N.S. Prospective cognition in animals. Behav. Proc. 2009, 314-324.

46. Balbontín, J.; Møller, A.P.; Hermosell, I.G.; Marzal, A.; Reviriego, M.; de Lope, F. Individual responses in spring arrival date to ecological conditions during winter and migration in a migratory bird. J. Anim. Ecol. 2009, 78, 981-989.

47. Leimar, O.; Hammerstein, P.; van Dooren, T.J. M. A New Perspective on Developmental Plasticity and the Principles of Adaptive Morph Determination. Am. Nat.t 2006, 167, 367-376.

48. Lof, M.E.; Reed, T.E.; McNamara, J.M.; Visser, M.E. Timing in a fluctuating environment: environmental variability and asymmetric fitness curves can lead to adaptively mismatched avian reproduction. Proc. R. Soc. B 2012, 279, 3161-3169.

49. Gottlieb, D.H.; Coleman, K.; McCowan, B. The effects of predictability in daily husbandry routines on captive rhesus macaques (Macaca mulatta). Appl. Anim. Behav. Sci. 2013, 143, 117-127.

50. Janssena, M.; Ostromb, E. Resilience, vulnerability, and adaptation: A cross-cutting theme of the International Human Dimensions Programme on Global Environmental Change. Global Environmen. Change 2009, 16, 237-239.

51. Preston, B.L.; Yuen, E.J.; Westaway, R.M. Putting vulnerability to climate change on the map: a review of approaches, benefits, and risks. Sustain. Sci. 2011, 6, 177-202.

52. Chevin, L.-M.; Lande, R.; Mace, G.M. Adaptation, Plasticity, and Extinction in a Changing Environment: Towards a Predictive Theory. PLoS Biol. 2010, 8, e1000357.

53. Richter, K.; Haslbeck, M.; Buchner, J. The Heat Shock Response: Life on the Verge of Death. Mol. Cell 2010, 40, 253-266. 
54. Warren, M.S.; Hill, J.K.; Thomas, J.A.; Asher, J.; Fox, R.; Huntley, B.; Roy, D.B.; Telfer, M.G.; Jeffcoate, S.; Harding, P.; et al. Rapid responses of British butterflies to opposing forces of climate and habitat change. Nature 2001, 414, 65-69.

55. Moran, D.T.; Dias, G.M.; Marshall, D.J. Associated costs and benefits of a defended phenotype across multiple environments. Funct. Ecol. 2010, 24, 1299-1305.

56. Ghalambor, C.K.; McKay, J.K.; Carroll, S.P.; Reznick, D.N. Adaptive versus non-adaptive phenotypic plasticity and the potential for contemporary adaptation in new environments. Funct. Ecol. 2007, 21, 394-407.

57. Pulido, F. Phenotypic changes in spring arrival: Evolution, phenotypic plasticity, effects of weather and condition. Clim. Res. 2007, 35, 5-23.

58. Brook, B.W.; Sodhi, N.S.; Bradshaw, C.J.A. Synergies among extinction drivers under global change. Trends Ecol. Evol. 2008, 23, 453-460.

59. Jenssen, B.M. Endocrine-Disrupting Chemicals and Climate Change: A Worst-Case Combination for Arctic Marine Mammals and Seabirds? Environ. Health Persp.s 2005, 114, 76-80.

60. Feil, R.; Fraga, M.F. Epigenetics and the environment: emerging patterns and implications. Nat. Rev. Genet. 2012, 13, 97-109.

61. Eriksen, S.; Aldunce, P.; Bahinipati, C.S.; Martins, R.D.; Molefe, J.I.; Nhemachena, C.; O’Brien, K.; Olorunfemi, F.; Park, J.; Sygna, L.; Ulsrud, K. When not every response to climate change is a good one: Identifying principles for sustainable adaptation. Clim. Develop. 2011, 3, 7-20.

62. Lande, R. Adaptation to an extraordinary environment by evolution of phenotypic plasticity and genetic assimilation. J. Evolution. Biol. 2009, 22, 1435-1446.

63. Hansen, M.M.; Olivieri, I.; Waller, D.M.; Nielsen, E.E.; Group, T.G.W. Monitoring adaptive genetic responses to environmental change. Mol. Ecol. 2012, 21, 1311-1329.

64. Wcislo, W.T. Behavioral Environments and Evolutionary Change. Annu. Rev. Ecol. Syst. 1989, 20, 137-169.

65. Davis, M.B. Range Shifts and Adaptive Responses to Quaternary Climate Change. Science 2001, 292, 673-679.

66. Gienapp, P.; Teplitsky, C.; Alho, J.S.; Mills, J.A.; Merilä, J. Climate change and evolution: disentangling environmental and genetic responses. Mol. Ecol. 2008, 17, 167-178.

67. Dingemanse, N.J.; Kazem, A.J.N.; Réale, D.; Wright, J. Behavioural reaction norms: animal personality meets individual plasticity. Trends Ecol. Evol. 2010, 25, 81-89.

68. Bauer, S.; Klaassen, M. Mechanistic models of animal migration behaviour-their diversity, structure and use. J. Anim. Ecol. 2013, in press.

69. Dingle, H. Rowley Review: Bird migration in the southern hemisphere: A review comparing continents. Emu 2008, 108, 341-359.

70. Ewen, J.G.; Armstrong, D.P.; Parker, K.A.; Seddon, P.J. Reintroduction Biology: Integrating Science and Management; John Wiley \& Sons: West-Sussex, UK, 2011.

71. Serrano, D.; Tella, J.L. Lifetime fitness correlates of natal dispersal distance in a colonial bird. J. Anim. Ecol. 2012, 81, 97-107.

72. Bilton, D.T.; Paula, J.; Bishop, J.D.D. Dispersal, Genetic Differentiation and Speciation in Estuarine Organisms. Estuar. Coast. Shelf S. 2002, 55, 937-952. 
73. Switzer, P.V. Factors affecting site fidelity in a territorial animal, Perithemis tenera. Anim. Behav.1997, 53, 865-877.

74. Bowler, D.E.; Benton, T.G. Causes and consequences of animal dispersal strategies: Relating individual behaviour to spatial dynamics. Biol. Rev. 2005, 80, 205-225.

75. Crooks, K.R.; Burdett, C.L.; Theobald, D.M.; Rondinini, C.; Boitani, L. Global patterns of fragmentation and connectivity of mammalian carnivore habitat. Phil. Trans. R. Soc. B 2011, $366,2642-2651$.

76. Komdeur, J. Conserving the seychelles warbler Acrocephalus sechellensis by translocation from Cousin Island to the islands of Aride and Cousine. Biol. Conserv. 1994, 67, 143-152.

77. Vercken, E.; Massot, M.; Sinervo, B.; Clobert, J. Colour variation and alternative reproductive strategies in females of the common lizard Lacerta vivipara. J. Evolution. Biol. 2007, 20, 221-232.

78. Oh, K.P.; Badyaev, A.V. Structure of Social Networks in a Passerine Bird: Consequences for Sexual Selection and the Evolution of Mating Strategies. Am. Nat. 2010, 176, E80-E89.

79. Bonte, D.; de la Peña, E. Evolution of body condition-dependent dispersal in metapopulations. J. Evolution. Biol. 2009, 22, 1242-1251.

80. Mery, F.; Burns, J.G. Behavioural plasticity: an interaction between evolution and experience. Evol. Ecol. 2010, 24, 571-583.

81. Piersma, T.; Drent, J. Phenotypic flexibility and the evolution of organismal design. Trends Ecol. Evol. 2003, 18, 228-233.

82. Dingemanse, N.J.; Bouwman, K.M.; Van de Pol, M.; Van Overveld, T.; Patrick, S.C.; Matthysen, E.; Quinn, J.L. Variation in personality and behavioural plasticity across four populations of the great tit Parus major. J. Anim. Ecol. 2012, 81, 116-126.

83. Wolf, M.; Doorn, G.S. van; Weissing, F.J. Evolutionary emergence of responsive and unresponsive personalities. Proc. Nutl. Acad. Sci. USA 2008, 105, 15825-15830.

84. Gross, K.; Pasinelli, G.; Kunc, H.P. Behavioral Plasticity Allows Short-Term Adjustment to a Novel Environment. Am. Nat.t 2010, 176, 456-464.

85. Jones, C.G.; Lawton, J.H.; Shachak, M. Organisms as Ecosystem Engineers. Oikos 1994, 69, 373.

86. Casas-Crivillé, A.; Valera, F. The European bee-eater (Merops apiaster) as an ecosystem engineer in arid environments. J. Arid Environ. 2005, 60, 227-238.

87. Wright, J.P.; Jones, C.G.; Flecker, A.S. An ecosystem engineer, the beaver, increases species richness at the landscape scale. Oecologia 2002, 132, 96-101.

88. Charmantier, A.; Garant, D. Environmental quality and evolutionary potential: lessons from wild populations. Proc. R. Soc. B 2005, 272, 1415-1425.

89. Stuart-Fox, D.; Moussalli, A. Camouflage, communication and thermoregulation: lessons from colour changing organisms. Phil. Trans. R. Soc. B 2009, 364, 463-470.

90. Reed, W.L.; Clark, M.E. Beyond Maternal Effects in Birds: Responses of the Embryo to the Environment. Integr. Comp. Biol. 2011, 51, 73-80.

91. Warkentin, K.M. Plasticity of Hatching in Amphibians: Evolution, Trade-Offs, Cues and Mechanisms. Integr. Comp. Biol. 2011, 51, 111-127.

92. Monaghan, P. Early growth conditions, phenotypic development and environmental change. Phil. Trans. R. Soc. B 2008, 363, 1635-1645. 
93. Beldade, P.; Mateus, A.R.A.; Keller, R.A. Evolution and molecular mechanisms of adaptive developmental plasticity. Mol. Ecol. 2011, 20, 1347-1363.

94. Hofmann, G.E.; Todgham, A.E. Living in the Now: Physiological Mechanisms to Tolerate a Rapidly Changing Environment. Annu. Rev. Physiol. 2010, 72, 127-145.

95. Møller, A.P.; Szép, T. Rapid evolutionary change in a secondary sexual character linked to climatic change. J. Evolution. Biol. 2005, 18, 481-495.

96. Price, T.D.; Qvarnstrom, A.; Irwin, D.E. The role of phenotypic plasticity in driving genetic evolution. P. R.l Soc. B 2003, 270, 1433-1440.

97. Richter, S.; Kipfer, T.; Wohlgemuth, T.; Guerrero, C.C.; Ghazoul, J.; Moser, B. Phenotypic plasticity facilitates resistance to climate change in a highly variable environment. Oecologia 2012, 169, 269-279.

98. Mller, A.P.; Biard, C.; Karadas, F.; Rubolini, D.; Saino, N.; Surai, P.F. Maternal effects and changing phenology of bird migration. Clim. Res. 2011, 49, 201-210.

99. Bernardo, J. Maternal Effects in Animal Ecology. Amer. Zool. 1996, 36, 83-105.

100. Meylan, S.; Miles, D.B.; Clobert, J. Hormonally mediated maternal effects, individual strategy and global change. Phil. Trans. R. Soc. B 2012, 367, 1647-1664.

101. Wells, J.C.K. An evolutionary perspective on the trans-generational basis of obesity. Ann. Hum. Biol. 2011, 38, 400-409.

102. Taborsky, B. Mothers Determine Offspring Size in Response to Own Juvenile Growth Conditions. Biol. Lett. 2006, 2, 225-228.

103. Räsänen, K.; Laurila, A.; Merilä, J. Maternal investment in egg size: Environment- and population-specific effects on offspring performance. Oecologia 2005, 142, 546-553.

104. Mousseau, T.A.; Fox, C.W. The adaptive significance of maternal effects. Trends Ecol. Evol. 1998, 13, 403-407.

105. Crean, A.J.; Marshall, D.J. Coping with environmental uncertainty: Dynamic bet hedging as a maternal effect. Phil. Trans. R. Soc. B 2009, 364, 1087-1096.

106. Burgess, S.C.; Marshall, D.J. Temperature-induced maternal effects and environmental predictability. J. Exp. Biol. 2011, 214, 2329-2336.

107. Hoyle, R.B.; Ezard, T.H.G. The benefits of maternal effects in novel and in stable environments. J. R. Soc. Interface 2012, 9, 2403-2413.

108. Candolin, U.; Salesto, T.; Evers, M. Changed environmental conditions weaken sexual selection in sticklebacks. J. Evolution. Biol. 2007, 20, 233-239.

109. Reser, J.P.; Swim, J.K. Adapting to and coping with the threat and impacts of climate change. Am. Psychol. 2011, 66, 277-289.

110. Wingfield, J.C.; Mukai, M. Endocrine disruption in the context of life cycles: Perception and transduction of environmental cues. Gen. Comp. Endocr. 2009, 163, 92-96.

111. Bjærke, O.; Østbye, K.; Lampe, H.M.; Vøllestad, L.A. Covariation in shape and foraging behaviour in lateral plate morphs in the three-spined stickleback. Ecol. Freshw. Fish 2010, 19, 249-256.

112. McKinnon, J.S.; Rundle, H.D. Speciation in nature: The threespine stickleback model systems. Trends Ecol. Evol. 2002, 17, 480-488. 
113. Harcourt, J.L.; Biau, S.; Johnstone, R.; Manica, A. Boldness and Information Use in ThreeSpined Sticklebacks. Ethology 2010, 116, 440-447.

114. Bell, A.M.; Stamps, J.A. Development of behavioural differences between individuals and populations of sticklebacks, Gasterosteus aculeatus. Anim. Behav. 2004, 68, 1339-1348.

115. Svanbäck, R.; Schluter, D. Niche specialization influences adaptive phenotypic plasticity in the threespine stickleback. Am. Nat. 2012, 180, 50-59.

116. Heuschele, J.; Mannerla, M.; Gienapp, P.; Candolin, U. Environment-dependent use of mate choice cues in sticklebacks. Behav. Ecol. 2009, 20, 1223-1227.

117. Garduño-Paz, M.V.; Couderc, S.; Adams, C.E. Habitat complexity modulates phenotype expression through developmental plasticity in the threespine stickleback. Biol. J. Linn. Soc. 2010, 100, 407-413.

118. Baker, J.A.; Foster, S.A. Phenotypic plasticity for life history traits in a stream population of the threespine stickleback, Gasterosteus aculeatus L. Ecol. Freshw Fish 2002, 11, 20-29.

119. Day, T.; McPhail, J.D. The effect of behavioural and morphological plasticity on foraging efficiency in the threespine stickleback (Gasterosteus sp.). Oecologia 1996, 108, 380-388.

120. Langenhof, M.B.W.; Komdeur, J. Small variations in early-life environment affect adaptive behaviour in response to obstructed foraging conditions for three-spined sticklebacks. 2013, under Review.

(C) 2013 by the authors; licensee MDPI, Basel, Switzerland. This article is an open access article distributed under the terms and conditions of the Creative Commons Attribution license (http://creativecommons.org/licenses/by/3.0/). 